\title{
Hardening and Dynamic Recovery During Hot Compression Test of Copper Simulated as Viscoplastic Material
}

\author{
Gabriel Torrente Prato ${ }^{a *}$ (1) \\ ${ }^{a}$ Universidad ECCI, Cra. 19 No. 49-20, Código Postal 111311, Bogotá, Colombia
}

Received: May 04, 2019; Revised: August 22, 2019; Accepted: October 02, 2019

\begin{abstract}
The Norton-Bailey equation was used to simulate by finite elements the hardening and dynamic recovery of copper during the hot compression tests. The constants of Norton-Bailey equation were determined from the Voce-Kocks model. The simulation assumes a Mortar Contact with Coulomb friction and axial symmetry. Numerical results were compared with experiments. Six compression tests were carried out at $804 \mathrm{~K}$, three with a strain rate of $0.1 \mathrm{~s}^{-1}$ and three with a strain rate of $1 \mathrm{~s}^{-1}$. The results show: The differences between the experiments and the simulations are less than $7.69 \%$ for strain rates of $0.1 \mathrm{~s}^{-1}$, and less than $0.67 \%$ for strain rates of $1 \mathrm{~s}^{-1}$. This shows that the simulation of hardening and dynamic recovery of hot copper is possible with the Norton-Bailey equation. Better numerical results were obtained when the behavior of copper is typical of hardening and dynamic recovery, and this happen for high values of strain rates.
\end{abstract}

Keywords: hot compression, viscoplasticity, copper, finite element, Voce-Kocks, Norton-Bailey, hardening and dynamic recovery.

\section{Introduction}

Hot forming is one of the most popular industrial processes to obtain metal products. ${ }^{1}$ The flow behavior of metals during hot forming reaches a saturation state due to the simultaneous compensation between the hardening and softening mechanisms. The softening is due to two mechanisms: dynamic recovery and recrystallization. ${ }^{1}$ Both are considered as "dynamic" and they occur simultaneously.

Dynamic recovery involves the annihilation of dislocations, as well as their rearrangement and formation of stable subgrain structures but without forming of new grains. ${ }^{2}$

Dynamic recovery slows down the hardening by increasing the rate of annihilation of dislocations until earn a steady state, moment in which happen a compensation between generation and annihilation of dislocation. ${ }^{2}$

In some materials, such as copper and alloys (i.e. low stacking fault energy metals), the dynamic recovery is slow. This causes an increase of the dislocation density with the strain. Eventually the local increase of dislocations density will allow the nucleation of new grains, moment when the dynamic recrystallization will begin., ${ }^{2,3}$

The Norton-Bailey equation has been widely used to describe the behavior of viscoplastic materials on creep test. May et al..$^{4}$ proposed a two-dimensional statistical regression of a power law to find the constants of Norton-Bailey equation. This work used the proposed made by May et al. ${ }^{4}$

The simulation made in this work seeks to clarify the effect of temperature, strain rate and friction on the hot flow curves of the hot compression test.
The aim of this work is introduced how the flow strength properties of hardening and dynamic recovery copper at relatively high temperature in hot compression tests can be explained in terms of the Norton-Baileys equation.

\section{Numerical Simulation}

Voce $^{5}$ in 1955 proposed an empirical equation to describe the first stage of softening in hot metals. In 1977 Kocks complemented the studies of Voce. ${ }^{6}$ Since then this has been knowing as the Voce-Kocks model and has been accepted to describe the mechanical behavior of hot metals during hardening and dynamic recovery, and it can be written as: ${ }^{3}$

$$
\sigma_{i}=\sigma_{s a t}\left[1-e^{\left(\omega \varepsilon_{i}\right)}\right]^{0.5}
$$

Relationships between the $\sigma_{s a t}$ (saturation stress), the correlation factor $\omega$ (also called "softening" parameter), $Z$ (Zenner-Hollomon parameter), $m(T)$ (shear modulus) and other material constants have been proposed in the literature: ${ }^{3,7}$

$$
\begin{gathered}
\sigma_{\text {sat }}=m(T)\left(\frac{U}{\omega}\right)^{0.5} \\
\omega=k_{\omega} Z^{m_{\omega}} \\
m(T)=\frac{E(T)}{2(1+v)} \\
E(T)=2(1+v) m_{0}\left\{1+\left(\frac{T-300}{T_{m}}\right)\left(\frac{T_{m} d m}{m_{0} d T}\right)\right\}
\end{gathered}
$$


Where $E(T)$ is the Young modulus, $m(T)$ is the shear modulus, $T_{m}$ is the melting temperature, (1356 K for copper), $v$ is the Poisson coefficient ( 0.34 for copper), $k_{\omega}$ and $m_{\omega}$ and are empirical material constants for copper for each specific strain rate $(\dot{\varepsilon}) .^{3}$

Garcia et al. ${ }^{3}$ concluded that the hardening parameter $U$ can be written as functions of the $Z$ and material constants:

$$
U=K_{U} Z^{M_{v}}
$$

Being the Zenner-Hollomon parameter: ${ }^{3}$

$$
Z=\dot{\varepsilon} \cdot \exp \left(\frac{Q_{s d}}{R T}\right)
$$

Where $\dot{\varepsilon}$ is the strain rate, $Q_{s d}$ is the activation energy of self-diffusion of copper, $R$ is the ideal gas constant and $T$ is the temperature.

The Voce-Kocks model has been used for hot tensile test by Choudhary et al. ${ }^{8}$ and Angella et al..$^{9}$ Al-Abedy et $a l .{ }^{10}$ in 2018 proposed the Voce-Kocks model to study the viscoplastic behavior during creep testing, showing a possible relation between the behavior during creep and hot tests.

Choudhary et al. ${ }^{8}$ studied the mechanical behavior of $\mathrm{P} 9$ steel in the temperature range $300-873 \mathrm{~K}$. They concluded that Voce equation (equation 1) is a good alternative to describe the mechanical behavior of this hot steel, including for saturation states as it happens in dynamic recrystallization.

Angella et al. ${ }^{9}$ described the tensile test curves of an austenitic stainless steel (AISI 316L) through the Voce-Kocks model in the temperature range $700-1000^{\circ} \mathrm{C}$ with strain rates between $10^{-2}$ and $10^{-5} \mathrm{~s}^{-1}$. They concluded that the Voce-Kocks model can describe the stress-strain curves inclusive for large strains.

Abedy et al. ${ }^{10}$ used the Kocks model to simulate the small punch creep behavior of the $\mathrm{P} 91$ steel at $600{ }^{\circ} \mathrm{C}$. Their numerical results showed the versatility and good predictive capability of the model for representing the visco-plasticity behavior of P91 steel at $600{ }^{\circ} \mathrm{C}$.

The Voce-Kocks model was used in this work to determine the Norton-Bailey equation constants. The Norton-Bailey equation can be written as: ${ }^{4,11}$

$$
\varepsilon=\left(A \sigma^{n}\right) t^{m}
$$

$\varepsilon, \sigma$ and $t$ are strain, stress and time, respectively.

The Norton-Bailey equation constants: $A, m$ and $n$ (equation 8 ) were determined using the method proposed by May et al. They used a statistical analysis of bivariant regression based on time to determine the Norton-Bailey constants as follows: ${ }^{4}$

$$
n=\frac{k \sum_{i=1}^{k}\left[\ln \left(\sigma_{i}\right) \ln \left(\varepsilon_{i}\right)\right]-\sum_{i=1}^{k}\left[\ln \left(\sigma_{i}\right)\right] \sum_{i=1}^{k}\left[\ln \left(\varepsilon_{i}\right)\right]}{k \sum_{i=1}^{k}\left[\ln \left(\sigma_{i}\right)\right]^{2}-\left\{\sum_{i=1}^{k}\left[\ln \left(\sigma_{i}\right)\right]\right\}^{2}}
$$

$$
\begin{gathered}
m=\frac{k \sum_{i=1}^{k}\left[\ln \left(t_{i}\right) \ln \left(\varepsilon_{i}\right)\right]-\sum_{i=1}^{k}\left[\ln \left(t_{i}\right)\right] \sum_{i=1}^{k}\left[\ln \left(\varepsilon_{i}\right)\right]}{k \sum_{i=1}^{k}\left[\ln \left(t_{i}\right)\right]^{2}-\left\{\sum_{i=1}^{k}\left[\ln \left(t_{i}\right)\right]\right\}^{2}} \\
A=e^{\sum_{i=1}^{k}\left[\ln \left(\varepsilon_{i}\right)\right]-(1) \sum_{i=1}^{k}\left[\ln \left(\sigma^{n} t^{m}\right)_{i}\right]} \\
k
\end{gathered}
$$

The Voce-Kocks model (equations 1 to 7) was used to calculate the value of $s_{i}$ for each $e_{i}$, respectively, for a specific temperature $(T)$ and strain rate $(\dot{\varepsilon})$.

Knowing that was calculated the time $\left(t_{i}\right)$ required to reach the respective strain $\left(e_{i}\right)$. With this way we obtain different points $\left(s_{i}, e_{i}, t_{i}\right)$, for a specific temperature, independently of the strain rate value.

Then with the points $\left(s_{i}, e_{i}, t_{i}\right)$ and the equations 9 to 11 we calculated the Norton-Bailey constants for each specific temperature. The results are showing in the Table 1.

Table 1. Norton-Bailey constants for copper.

\begin{tabular}{cccc}
\hline$T\left({ }^{\circ} \mathrm{C}\right)$ & $A$ & $n$ & $m$ \\
\hline 370 & $1.232 \mathrm{E}-05$ & 3.0541 & 0.4780 \\
480 & $3.829 \mathrm{E}-05$ & 3.3534 & 0.4780 \\
500 & $4.544 \mathrm{E}-05$ & 3.4020 & 0.4780 \\
520 & $5.379 \mathrm{E}-05$ & 3.4488 & 0.4780 \\
540 & $6.354 \mathrm{E}-05$ & 3.4940 & 0.4780 \\
580 & $8.811 \mathrm{E}-05$ & 3.5794 & 0.4780 \\
620 & $1.213 \mathrm{E}-04$ & 3.6586 & 0.4780 \\
670 & $1.790 \mathrm{E}-04$ & 3.7495 & 0.4780 \\
\hline
\end{tabular}

* for $\sigma\left[\mathrm{Kgf} / \mathrm{mm}^{2}\right]$ and de $t[\mathrm{~s}]$ in eq. 8

Figure 1 are the Norton-Bailey constants (equations 9 to 11) with temperature.

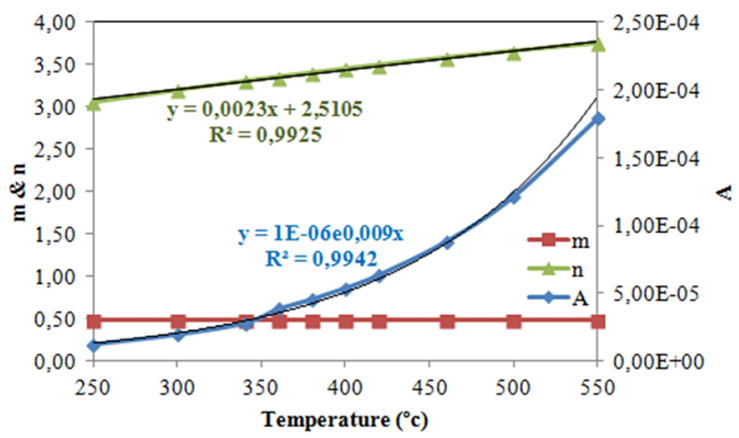

Figure 1. Norton-Bailey constants as a function of temperature for copper with strain rates between 0.1 and $1 \mathrm{~s}^{-1}$.

Figure 2 is the behavior of the Norton-Bailey equation (equation 8) for copper at $520^{\circ} \mathrm{C}$. 


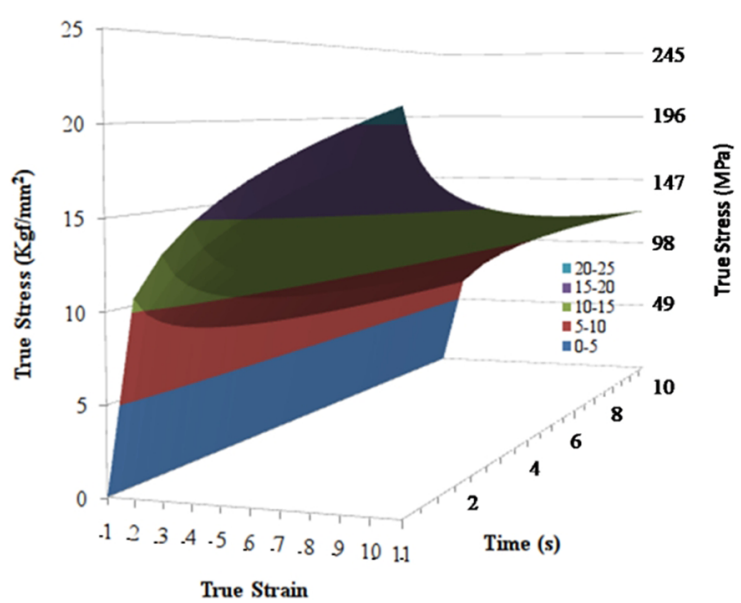

Figure 2. Norton-Bailey equation for copper at $520^{\circ} \mathrm{C}$ for strain rates between 0.1 and $1 \mathrm{~s}^{-1}$.

Figure 3 are the Stress-Strain curves obtained with the Voce-Kocks model (VK) (equations 1 to 6) and with NortonBailey model (NB) (equations 7 to 10).

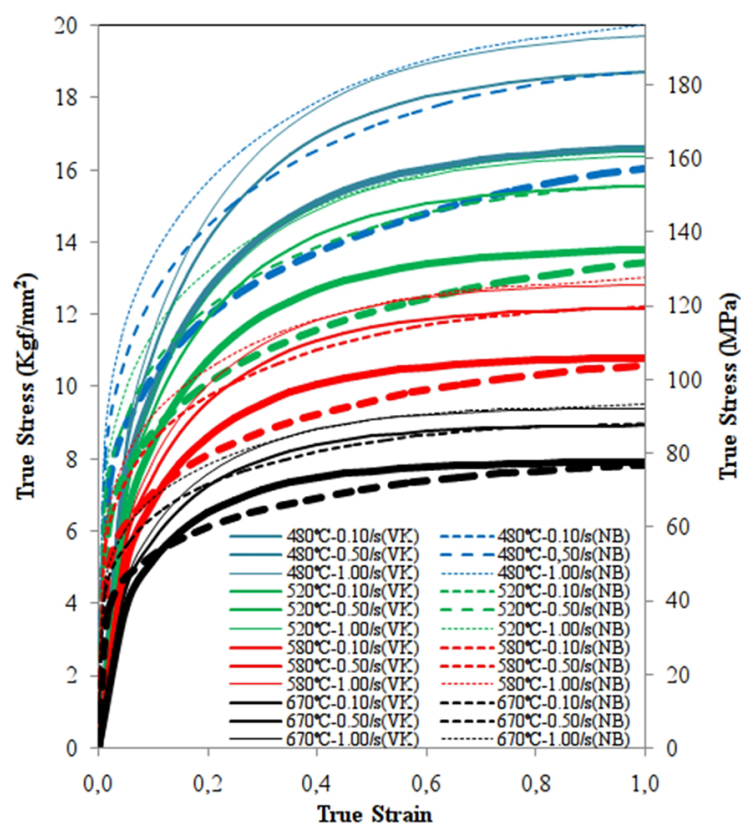

Figure 3. Stress vs. Strain curves obtained from Voce-Kocks (VK) and from the Norton-Bailey (NB) for $480,520,580$ and $670{ }^{\circ} \mathrm{C}$ and for strain rates of $0.1,0.5$ and $1 \mathrm{~s}^{-1}$.

Figure 2 shows for a strain of $1 \mathrm{~s}^{-1}$ and at $1 \mathrm{~s}$ a stress of $17.29 \mathrm{Kgf} / \mathrm{mm}^{2}(170 \mathrm{MPa})$. This value corresponds to the end of the lines obtained with equations of Voce-Kocks and Norton-Bailey for a strain rate of $1 \mathrm{~s}^{-1}$, thinnest green lines and thinnest dash green line, respectively, in Figure 3.

Figure 2 shows for a strain of 1 and at $10 \mathrm{~s}$ a stress of $12.57 \mathrm{Kgf} / \mathrm{mm}^{2}(123 \mathrm{MPa})$. This value corresponds to the end of the lines obtained by the equations of Voce-Kocks and Norton-Bailey for a strain rate of $0.1 \mathrm{~s}^{-1}$, thickest green line and thickest dash green line, respectively, in Figure 3.
Figures 2 and 3 show the difference between NortonBailey and Voce-Kocks models, being the difference between them less than $7.69 \%$, being higher for higher values of temperature and lower values of strain rates, and at the hardening-dynamic recovery transition.

Liu et al. ${ }^{12}$, Jin et al. ${ }^{13}$, among others, have used the Norton-Bailey model to simulate the creep tests.

Liu et al. ${ }^{12}$ studied the creep behavior of P91-steel. They proposed a new model based on the Norton-Bailey creep law. They concluded that their model can be used to describe all creep stages for P91- steel.

Jin et al. ${ }^{13}$ described the high temperature compressive creep behavior of refractories (magnesia-chromite) with the Norton-Bailey creep law.

Creep consists of three stages: The first one is the transient creep region and consists on the strain hardening of material. The secondary creep or steady-state creep is when the materials experiment a competitive processes of strain hardening and dynamic recovery. The tertiary creep is an acceleration of hardening until ultimate failure. ${ }^{14}$ The metallurgical events happened in the material during the first two stages on creep test and on hot compression test are similar. Therefore, it is expected that the mechanical behavior during the first two stages on creep test and on hot compression test also will be similar.

Bueno et al. ${ }^{15}$ found a remarkable compatibility between creep and the hot tensile behavior, showing a coherent transition from the region of power-law to exponential creep behavior.

The novelty of this works is to propose the Norton-Bailey model to simulate the hardening and dynamic recovery of copper during the hot compression test.

\section{Experimental Procedure}

The copper was characterized by chemical analysis, mechanical and metallographic tests. The chemical analysis was carried out with the atomic emission spectrophotometer SpectroLab Junior; the results are showed in Table 2. The oxygen content in copper was not determined.

Table 2. Chemical composition of copper.

\begin{tabular}{ccccccc}
\hline $\mathrm{Pb}$ & $\mathrm{Sn}$ & $\mathrm{P}$ & $\mathrm{Mn}$ & $\mathrm{Fe}$ & $\mathrm{Ni}$ & $\mathrm{Si}$ \\
\hline 14.4 & 4.9 & $<0.4$ & 2.7 & 25.6 & $<0.7$ & 1.2 \\
$\mathrm{Al}$ & $\mathrm{S}$ & $\mathrm{Be}$ & $\mathrm{Zr}$ & $\mathrm{Au}$ & $\mathrm{Sb}$ & $\mathrm{Mg}$ \\
19.9 & $<0.3$ & 0.1 & $<0.3$ & 1.6 & $<3$ & 5.5 \\
$\mathrm{Te}$ & $\mathrm{As}$ & $\mathrm{Cd}$ & $\mathrm{Bi}$ & $\mathrm{Ag}$ & & \\
$<5$ & $<0.6$ & $<0.7$ & $<2.5$ & 6.1 & & \\
NOTE: $\% \mathrm{w} / \mathrm{w} \times 10^{3}$, Balance to $100 \%$ of $\mathrm{Cu}$.
\end{tabular}

Six hot compression tests were carried out. The cylindrical copper samples were $\mathrm{D}_{0}=12.6 \mathrm{~mm}$ of diameter and $\mathrm{L}_{0}=18.9$ $\mathrm{mm}$ of length, being the slenderness ratio of $\mathrm{L}_{0} / \mathrm{D}_{0}=1.5$ according to ASTM E9-98. ${ }^{16}$ 
The hot compression tests were carried out at Simon Bolivar University-Venezuela, according to ASTM E 209$00 .{ }^{17}$ Two strain rates were tested; 0.1 and $1 \mathrm{~s}^{-1}$.

The hot compression tests were performed on the Universal Testing Machine MTS-312.31/227 with the oven ATS $® 2961$.

Figure 4 is the experimental setup where the hot compression tests were carried on.

The tests were carried out used graphite as a lubricant between the copper samples and the dies.

The temperatures of the tests with strain rate of $0.1 \mathrm{~s}^{-1}$ decreased from 548 to $528{ }^{\circ} \mathrm{C}(821$ to $801 \mathrm{~K})$, and decrease from 532 to $515^{\circ} \mathrm{C}(805$ to $788 \mathrm{~K})$ during the tests with strain rate of $1 \mathrm{~s}^{-1}$. The temperatures were measured experimentally and calculated numerically. The temperatures had an error less than $+/-3^{\circ} \mathrm{C} .1,18$

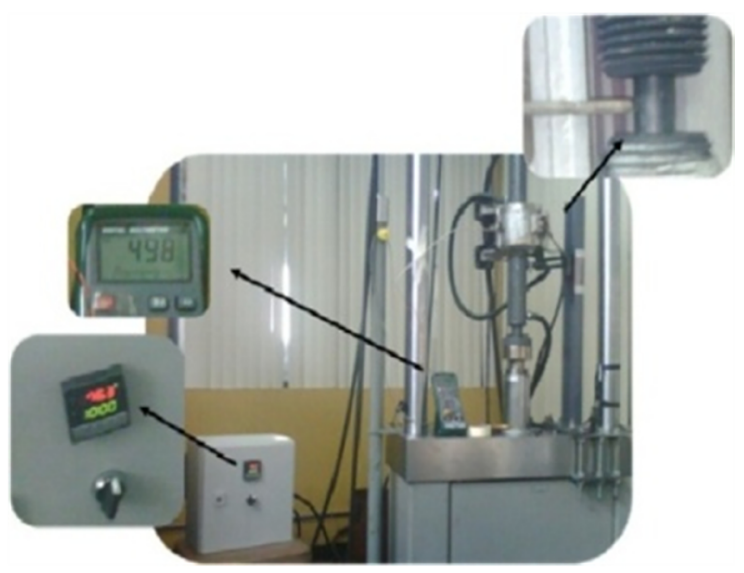

Figure 4. Experimental setup ${ }^{1}$

The experimental procedure was as follows: The oven was heated to a temperature of $540+/-8^{\circ} \mathrm{C}$. The copper was introduced inside the oven and a time of $20 \mathrm{~min}$ was waited to reach steady state, and then the tests begun. The total displacement of the tests was fixed to $11.9 \mathrm{~mm}$, this displacement was determined taking into account a final strain of -1 , and the time test was fixed to 1 second for tests with strain rate of $1 \mathrm{~s}^{-1}$, and 10 seconds for tests with strain rate of $0.1 \mathrm{~s}^{-1}$. Figure 5 are the load rates of the tests.

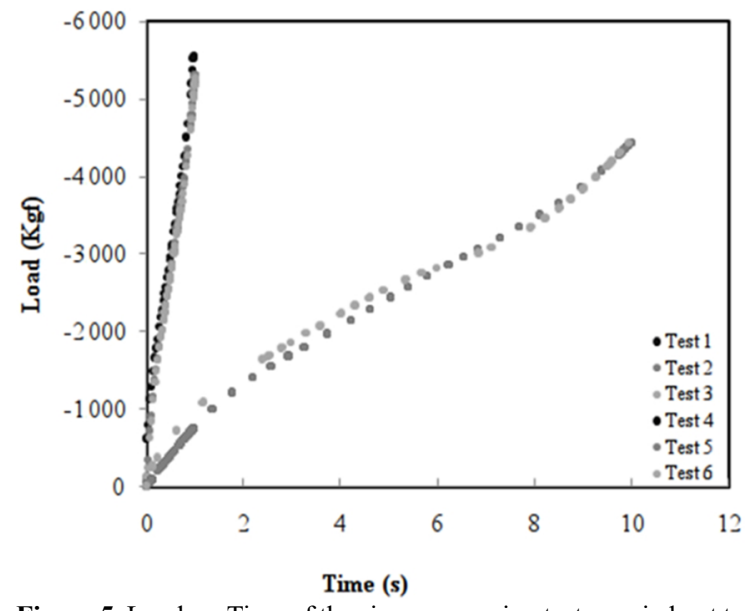

Figure 5. Load vs. Time of the six compression tests carried out to copper at $530+/-20^{\circ} \mathrm{C}$ with two strain rates: 1 and $0.1 \mathrm{~s}^{-1}$
The stress-strain curves were calculated taking into account two corrections:

The first is the correction for displacement. The real displacement was obtained subtracting to the experimental displacement the displacement at the beginning of the test during the contact adjustment and the elastic deflection of the load frame. The elastic deflection of the load frame was obtained experimentally loading die against die at $540^{\circ} \mathrm{C}$.

The second is related to the friction between the dies and the sample. The values of the true stresses were obtained with he Dieter friction correction (equation 12) ${ }^{19}$ and with the Torrente friction correction (equation 13). ${ }^{20}$

$$
\begin{gathered}
\sigma=\frac{C_{f}^{2} \sigma_{z}}{2\left[\exp \left(C_{f}\right)-C_{f}-1\right]} \\
e^{0.463 \mu}=\frac{D_{m}-D_{0}}{D_{v c p}-D_{0}}
\end{gathered}
$$

$C_{f}$ is the Coulomb stress distribution, $\sigma$ and $\sigma_{z}$ are the stress without and with friction, respectively, $\mu$ is the friction coefficient, $D_{0}$ and $D_{v c p}$ are the initial diameter and the diameter calculated with the volume conservation principle, respectively, $D_{m}$ is the maximum diameter or barreling diameter, which is used to determine the stress $\sigma$ with Torrente friction correction. The friction coefficient used was 0.18 . This value is obtained from the literature for copper-steel with lubrication. ${ }^{21,22}$

\section{Finite Element Analysis}

The mesh was made with $\mathrm{Gmsh}^{23}$, with an element size factor of 1.25. The finite element simulations were made with Calculix. ${ }^{24}$ The simulations were performed with a HP Pavilion dv6.

The hypotheses are:

a) The behavior is symmetrical. The behavior of top side is the same of the bottom. Then, the control volume is Figure 6.

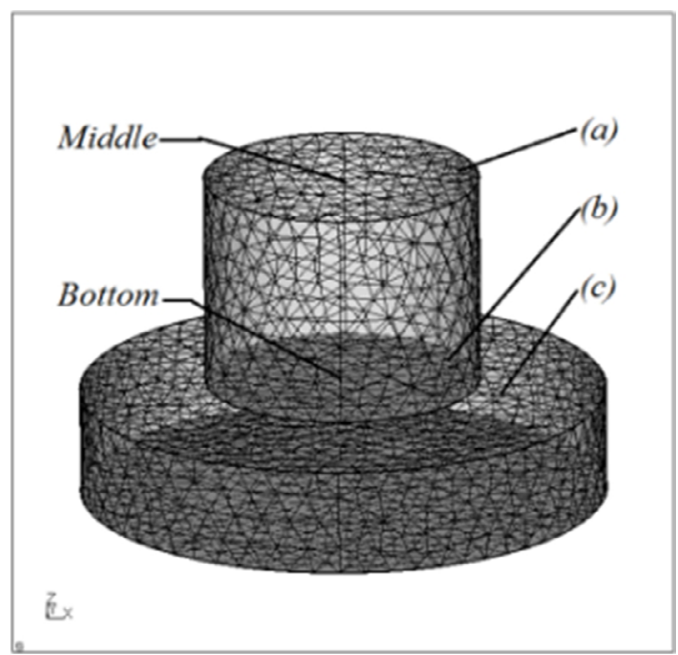

Figure 6. Mesh of the control volume in the finite element model. 
b) The dies are rigid.

c) The copper is simulated as viscoplastic material and its mechanical behavior is described by the Norton-Bailey equation (equation 7), and with a Poisson's ratio of $v=0.34 .{ }^{14}$

d) The temperature in the copper sample is assumed constant. The Norton-Bailey constants for copper are in Table 1.

e) The elastic recovery is zero.

The simulation has boundary conditions on three surfaces: (Figure 6)

a) The surface of the center of the sample. This surface is free to move and on it is applied the compression load. The load amplitude is a function of the time and it was taken from the experiments (see Figure 6). Another condition on this surface is the multiple point constraint type plane (MPC-PLANE). ${ }^{24}$

b) The bottom surface of the sample. This surface is free to move and it was defined to complete the contact pair with the die and mortar contact with Coulomb friction. Simulations were made with friction coefficients between 0.2 and 0.4 . The literature has reported values of $\mu$ near to 0.18 for kinetic or sliding friction coefficient, this value could be higher when the friction is static or sticky. ${ }^{25,22}$

c) The upper surface of the lower die. This surface has no degrees of freedom, and it was defined to complete the contact pair with the sample.

Figure 7 are the Stress vs. Strain curves experimentally calculated with a strain rate of $1 \mathrm{~s}^{-1}$ (gray dotted lines) and the Von Mises stress vs. Von Mises Equivalent Strain curves in the middle of the sample obtained from the simulation (green and red lines). The experimental stress was calculated taking into account the Dieter friction correction ${ }^{19}$ and the Torrente ${ }^{20}$ friction correction, equations 12 and 13 , respectively.

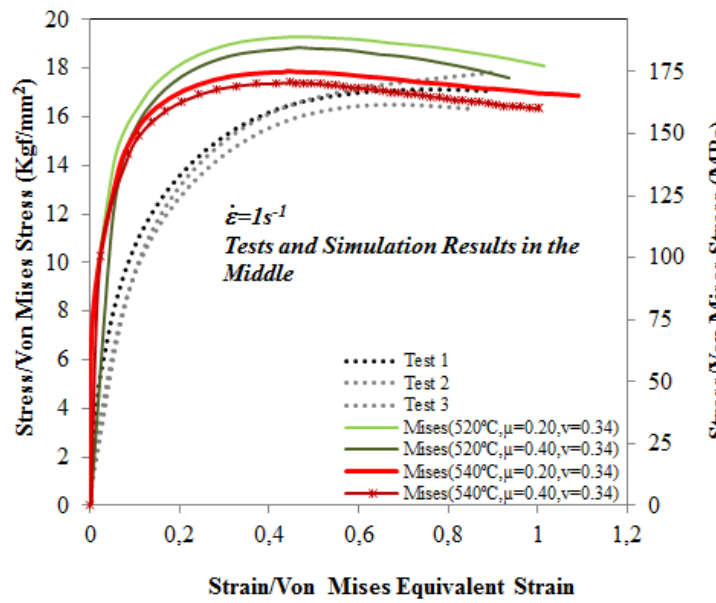

Figure 7. True stress vs. True strain curves from experiments (dotted lines), and Von Mises Stress vs. Von Mises Equivalent Strain curves in the middle of the sample from simulations (solid lines), all of them for tests at $540{ }^{\circ} \mathrm{C}$ and strain rate of $1 \mathrm{~s}^{-1}$.
The simulation shows that lower values of friction coefficient $(\mu=0.2)$ allow higher strains, higher strain rates, higher stresses and therefore higher hardening (light colors in Figure 7)

Figure 8 is a cut view of the Von Mises equivalent strain in the sample at $540{ }^{\circ} \mathrm{C}$, with a friction coefficient of 0.2 and a strain rate of $1 \mathrm{~s}^{-1}$, at $0.39 \mathrm{~s}$ (light red line in Figure 7).

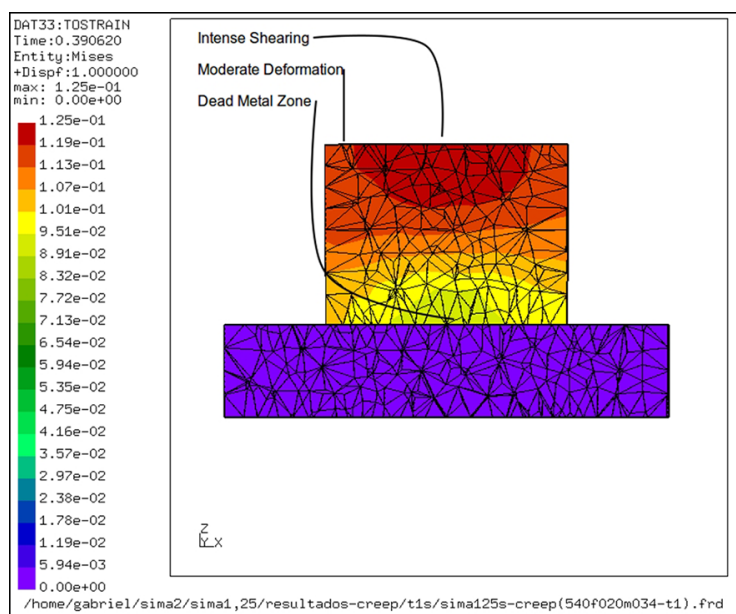

Figure 8. Cut view of the Von Mises equivalent strain for a copper at $540{ }^{\circ} \mathrm{C}$, tested under compression with a strain rate of $1 \mathrm{~s}^{-1}$, with a friction coefficient of 0.20 , and a Poisson's ratio of 0.34 , at $0.39 \mathrm{~s}$.

The simulation shows (Figure 8) the non-homogeneity of deformation in the sample caused by friction with a zone of low deformation on the bottom, a moderate deformation zone on the edges, and a zone of intense deformation in the middle. These three zones of deformation in the sample were described by Dieter. ${ }^{26}$

This non-homogeneity is also in the hardening. Figure 9 is the Von Mises Stress at $540{ }^{\circ} \mathrm{C}, \mu=0.2$, strain rate of $1 \mathrm{~s}^{-1}$, and at $0.39 \mathrm{~s}$ (light red line in Figure 7).

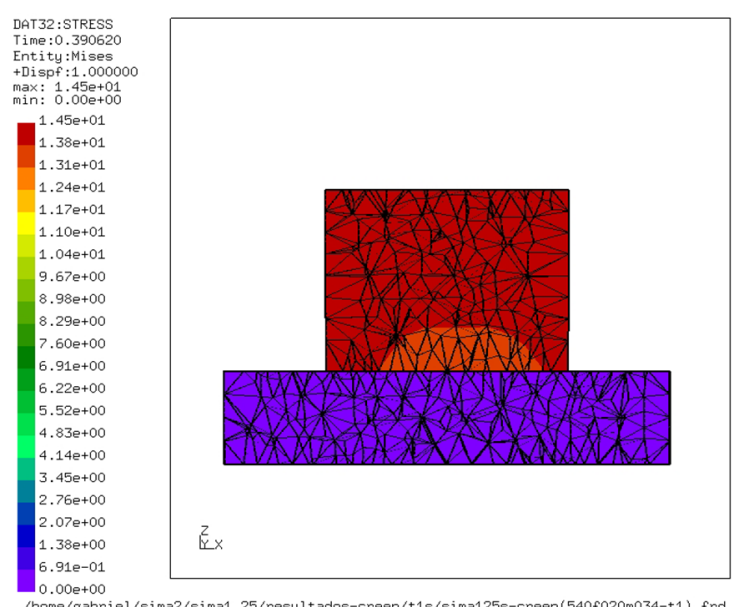

/home/gabriel/sima2/sima1, 25/resultados-creep/t1s/sima125s-creep (5400020m034-t1). frd

Figure 9. Cut view of Von Mises stress $\left[\mathrm{Kgf} / \mathrm{mm}^{2}\right]$ for a copper at $540{ }^{\circ} \mathrm{C}$, tested under compression with a strain rate of $1 \mathrm{~s}^{-1}$, with a friction coefficient of 0.20 , and a Poisson's ratio of 0.34 , at $0.39 \mathrm{~s}$. 
Figure 10 are the Von Mises stress vs. Time curves on the bottom of the sample. The experimental stress (gray dotted lines) also was calculated taking into account the Dieter friction correction $^{19}$ and the Torrente friction correction ${ }^{20}$.

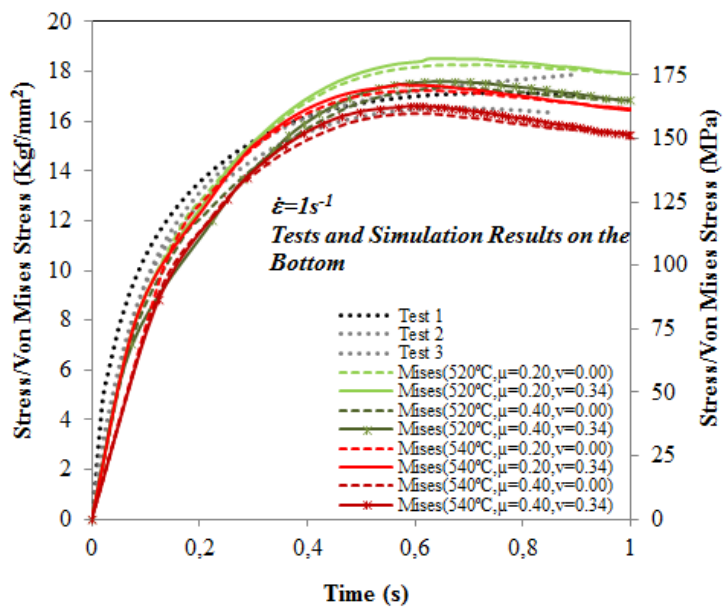

Figure 10. True stress vs. True Strain curves from experiments (dotted lines), and Von Mises Stress vs. Von Mises Equivalent Strain curves on the bottom of the sample from simulations (solid and dash lines), all of them for tests at $540^{\circ} \mathrm{C}$ and strain rate of $1 \mathrm{~s}^{-1}$.

Figure 11 are the results of Load vs. Displacement with a strain rate of $1 \mathrm{~s}^{-1}$.

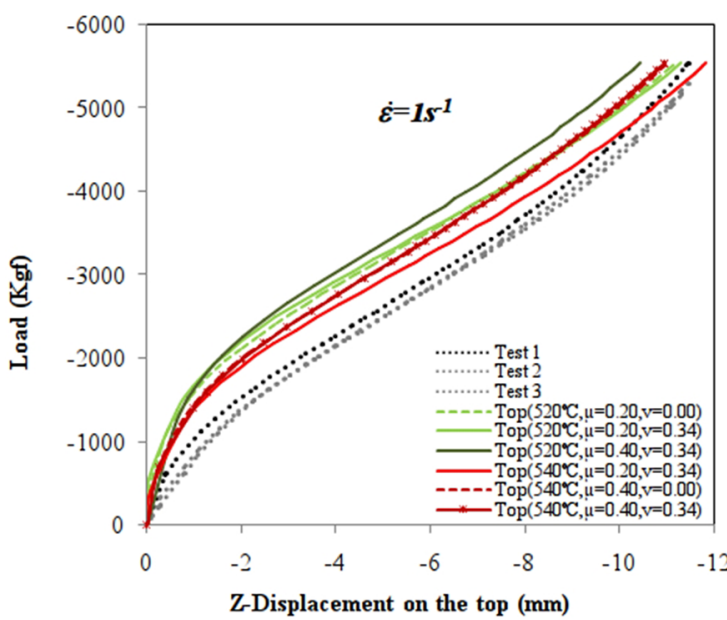

Figure 11. Load vs. Displacement for tests at $540^{\circ} \mathrm{C}$ with a strain rate of $1 \mathrm{~s}^{-1}$ obtained from the experiments (dotted lines), and from the simulation (solid and dash lines).

Figure 10 shows that Von Mises stress on the bottom is closer to the experimental measurements than in the middle (see Figure 7). The Von Mises stress on the bottom at $540{ }^{\circ} \mathrm{C}$ (light red line) is similar to the experiments. Therefore, possibly, the experimental measurements of mechanicals properties are ruled by the least hardened zone, the dead metal zone (see Figure 8). Figure 10 also shows the beginning of the dynamic recovery at $0.39 \mathrm{~s}$. This beginning of the dynamic recovery also is observed in the behavior of Load vs. Displacement (see Figure 11).
Figure 12 are the True Stress vs. True Strain curves obtained experimentally and the Von Mises Stress vs. Von Mises Equivalent Strain obtained from the simulation in the middle of the sample for a strain rate of $0.1 \mathrm{~s}^{-1}$.

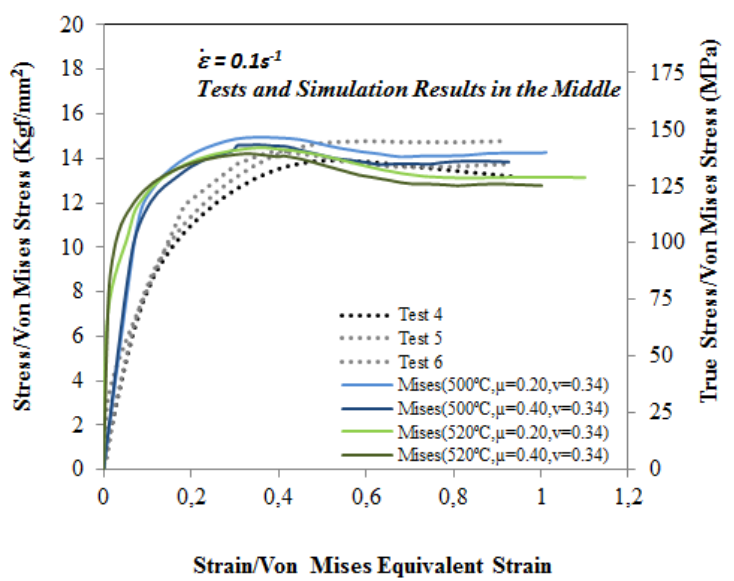

Figure 12. True Stress vs. True Strain curves measured experimentally (dotted lines), and Von Mises Stress vs. Von Mises Equivalent Strain curves in the middle of the sample calculated from simulations (solid lines), all of them tests at $540{ }^{\circ} \mathrm{C}$ and strain rate of $0.1 \mathrm{~s}^{-1}$.

Figure 13 are the True Stress measured experimentally and the Von Mises Stress calculated numerically on the bottom of the sample. The experimental stress also was calculated taking into account the friction corrections. ${ }^{19,20}$

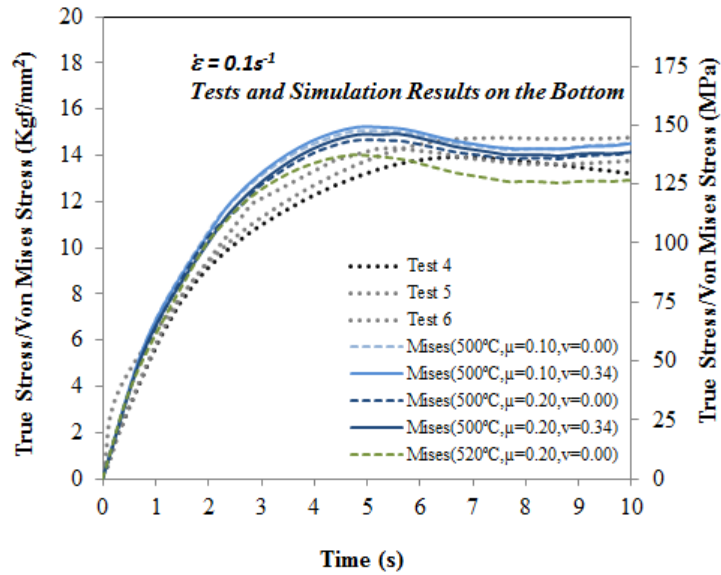

Figure 13. True stress vs. True Strain curves measured experimentally (dotted lines), and Von Mises Stress vs. Von Mises Equivalent Strain curves on the bottom of the sample calculated from simulations (solid and dash lines), all of them for tests at $540{ }^{\circ} \mathrm{C}$ and strain rate of $0.1 \mathrm{~s}^{-1}$.

Figure 13 shows that, at the beginning of the test, the simulation at $520^{\circ} \mathrm{C}$ and a friction coefficient of 0.20 (green dash line) is the best fit to experiments, with a differences between the simulation and tests less than $1.96 \mathrm{MPa}(1.52 \%)$, but after 4 seconds the simulation at $500^{\circ} \mathrm{C}$ (light blue line) is among the experimental measurements (dotted line). 
Figures 3, 10 and 13 show that the difference between the experiments, the Voce-Kocks model, the Norton-Bailey model and the simulation are less than $7.69 \%$ for strain rates of $0.1 \mathrm{~s}^{-1}$ and less than $0.67 \%$ for strain rates of $1 \mathrm{~s}^{-1}$. This shows that the Norton-Bailey model allows simulating the behavior of hardening and dynamic recovery of hot copper, obtaining better results when the mechanical behavior is typical of hardening and dynamic recovery, such as occurring with faster strain rates.

Figure 14 are the Load vs. Displacement curves for a strain rate of $0.1 \mathrm{~s}^{-1}$.

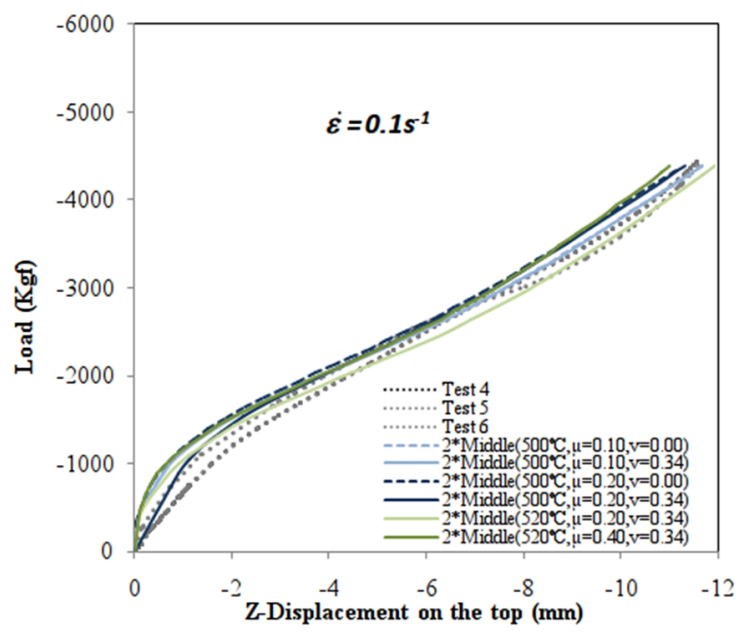

Figure 14. Load vs. Displacement for tests at $540{ }^{\circ} \mathrm{C}$ with a strain rate of $0.1 \mathrm{~s}^{-1}$ obtained from the experiments (dotted lines), and from the simulation (solid and dash lines).

Figure 14 shows that when the friction coefficient decreased, greater Z-Displacements are obtained. Figure 14 also shows that the Poisson's ratio does not affect appreciably the Load vs. Z-displacement. The differences between the experiments and the simulation at $500^{\circ} \mathrm{C}$ (light blue line) are $4.92 \%$.

Figure 15 is a cut view of Von Mises Equivalent Strain for a copper at $500^{\circ} \mathrm{C}$, tested under compression with a strain rate of $0.1 \mathrm{~s}^{-1}$, with a friction coefficient of 0.20 , Poisson's ratio of 0.34 , at $10 \mathrm{~s}$, or at the end of the test (Dark blue line in Figure 13).

Figure 15 shows the barreling of the sample at the end of the test at $500{ }^{\circ} \mathrm{C}$ with a strain rate of $0.1 \mathrm{~s}^{-1}$. This figure shows that at the end of the test the Von Mises Equivalent Strain in the middle is maximum and is 1.01 , and on the bottom is minimum and is 0.828 . The Von Mises Equivalent Strain on the bottom does not have a real relationship with the True Strain measured experimentally, then, we propose that a better way is based on time because the Von Mises Equivalent Strain in the Dead Metal Zone does not have a real comparison with the True Strain (see Figure 10 and 13).

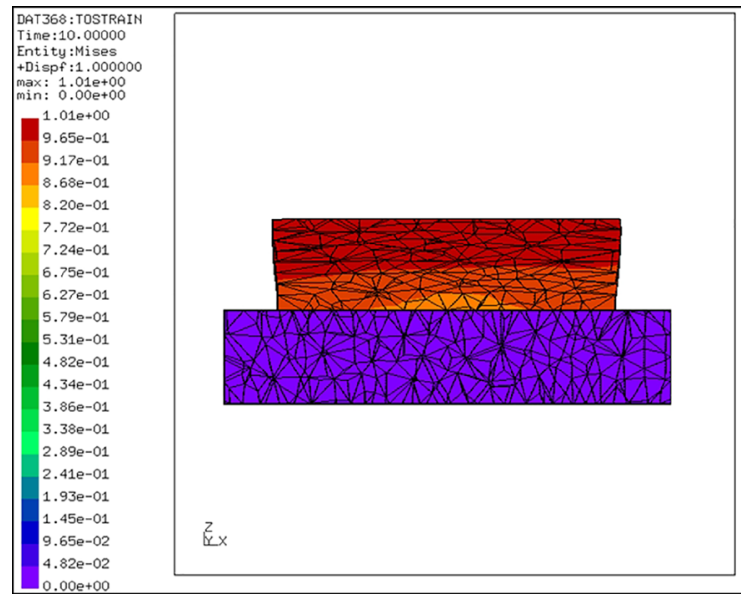

Figure 15. Cut view of the Von Mises Equivalent Strain for copper at $500{ }^{\circ} \mathrm{C}$, tested under compression with a strain rate of $0.1 \mathrm{~s}^{-1}$, with a friction coefficient of 0.20 , and a Poisson's ratio of 0.34 , at a time of $10 \mathrm{~s}$.

\section{Conclusions}

The differences between the Stress vs. Strain curves obtained from the experiments, from the Voce-Kocks model, from Norton-Bailey model, and from the simulations are less than $7.69 \%$ for strain rates of $0.1 \mathrm{~s}^{-1}$, and less than $0.67 \%$ for strain rates of $1 \mathrm{~s}-1$. This shows that with the Norton-Bailey equation is possible to simulate the behavior of hardening and dynamic recovery of hot copper, obtaining excellent results when the mechanical behavior is typical of hardening and dynamic recovery, such as occur to high strain rates.

The simulation shows that the friction causes a nonhomogeneous deformation in the sample during the hot compression tests. Therefore, the strain rate, the hardening and dynamic recovery are not uniform in the sample, generating a sample with non-homogeneous mechanical properties.

The experimental measurements of stress, possibly, are ruled by the least hardened zone in the sample, the dead metal zone.

\section{Acknowledgments}

I thank Prof Mary Torres from Universidad Simon BolivarVenezuela and Prof. Jose Maria Cabrera from Polytechnic University of Catalonia for intellectual contribution on this research. I thank Lab-E of Simon Bolivar UniversityVenezuela for providing the laboratory facilities.

This study was funded by Fundación Carolina, Decanato de Investigación y Desarrollo de la Universidad Simón Bolívar-Venezuela, Dirección de Desarrollo Profesoral de la Universidad Simón Bolívar-Venezuela and Universitat Politècnica de Catalunya. 


\section{References}

1. Torrente G, Torres M, Sanoja L. Efecto de la velocidad de deformación en la recristalización dinámica de un cobre ETP durante su compresión en caliente con temperatura descendente. Revista de Metalurgia. 2011;47(6):485-496. DOI: 10.3989/revmetalm.1143

2. Cabrera JM, Staia MH, eds. Aceros estructurales: procesamiento, manufactura y propiedades. Barcelona: CYTED; 2003.

3. Garcia Fernández VG. Constitutive relations to model the hot flow of commercial purity cooper. [thesis]. Barcelona: Universitat Politècnica de Catalunya; 2004.

4. May D, Gordon A, Segletes D. The Application of the NortonBailey Law for Creep Prediction Through Power Law Regression. In: Proceedings of ASME Turbo Expo 2013: Turbine Technical Conference and Exposition; 2013 Jun 3-7; San Antonio, TX, USA.

5. Voce E. A Practical Strain-Hardening Function. Metallurgia. 1955;51:219-226.

6. Cerrollaza M, Florez-López J, comps. Modelos Matemáticos en Ingeniería Moderna. Caracas: Universidad Central de Venezuela; 2000.

7. Frost H, Ashby M. Deformation-mechanism maps: The plasticity and creep of metals and ceramics. Oxford: Pergamon Press; 1982.

8. Choudhary BK, Christopher J, Samuel EI. Applicability of Kocks-Mecking approach for tensile work hardening in P9 steel. Materials Science and Technology. 2012;28(6):644-650. DOI: $10.1179 / 1743284711$ Y.0000000106

9. Angella G, Donnini R, Maldini M, Ripamonti D. Combination between Voce formalism and improved Kocks-Mecking approach to model small strains of flow curves at high temperatures. Materials Science and Engineering: A. 2014;594:381-388. DOI: $10.1016 /$ j.msea.2013.11.088

10. Al-Abedy HK, Jones IA, Sun W. Small punch creep property evaluation by finite element of Kocks-Mecking-Estrin model for P91 at elevated temperature. Theoretical and Applied Fracture Mechanics. 2018;98:244-254. DOI: https://doi.org/10.1016/j. tafmec.2018.10.006

11. Perzyna P. Fundamental problems in viscoplasticity. Advances in Applied Mechanics. 1966;9:244-377.

12. Liu F, Tang $P$, Kong $S$, Ling Z, Zheng M, Zhao L. Investigations on Creep Behavior of P91-Type Steel Using Combined Creep Damage Model. In: ASME 2013 Pressure Vessels and Piping Conference; 2013 Jul 14-18; Paris, France. DOI: 10.1115/PVP2013-97815

13. Jin S, Harmuth H, Gruber D. Compressive creep testing of refractories at elevated loads-Device, material law and evaluation techniques. Journal of the European Ceramic Society. 2014;34(15):4037-4042. DOI: https://doi.org/10.1016/j. jeurceramsoc.2014.05.034
14. Callister W. Materials Science and Engineering: An Introduction. $7^{\text {th }}$ ed. Hoboken: John Wiley \& Sons; 2007.

15. Bueno LO, Sobrinho JFR. Correlation between creep and hot tensile behaviour for $2.25 \mathrm{Cr}-1 \mathrm{Mo}$ steel from $500^{\circ} \mathrm{C}$ to $700^{\circ} \mathrm{C}$ Part 1: An Assessment According to usual Relations Involving stress, temperature, strain rate and Rupture Time. Matéria (Rio de Janeiro). 2012;17(3):1098-1108. DOI: http://dx.doi. org/10.1590/S1517-70762012000300007

16. ASTM International. ASTM E 9-09A - Standard Test Methods for Tension Testing of Metallic Materials at room temperature. In: ASTM Standards. Volume 03.01. West Conshocken: ASTM International; 2010.

17. ASTM International. ASTM E-209-00 - Standard Practice for Compression Tests of Metallic Materials at Elevated Temperatures with Conventional or Rapid Heating Rates and Strain Rates. In: ASTM Standards. Volume 03.01. West Conshocken: ASTM International; 2010.

18. Torrente-Prato G, Torres-Rodriguez M. Numerical and experimental preliminary study of temperature distribution in an electric resistance tube furnace for hot compression tests. DYNA. 2014;81(186):234-241. DOI: https://doi.org/10.15446/ dyna.v81n 186.40388

19. Dieter G. Mechanical Metallurgy. $3^{\text {rd }}$ ed. New York: McGrawHill; 1986.

20. Torrente G. Numerical and Experimental Studies of CompressionTested Copper: Proposal for a New Friction Correction. Materials Research. 2018;21(4):e20170905. DOI: http://dx.doi. org/10.1590/1980-5373-MR-2017-0905

21. Smith EA. Graphite and Boron Nitride ("White Graphite"): Aspects of Structure, Powder Shape and Purity. Powder Metallurgy. 1971;14(27):110-123.

22. The Engineering ToolBox. Friction and Friction Coefficients. Available from: $<$ https://www.engineeringtoolbox.com/frictioncoefficients-d 778.html>. Access in: 06/08/2018.

23. Geuzaine C, Remacle JF. Gmsh: a 3-D finite element mesh generator with built-in pre- and post-processing facilities. International Journal for Numerical Methods in Engineering. 2009;79(11):1309-1331. DOI: 10.1002/nme.2579

24. Dhondt G. CalculiX CrunchiX USER'S MANUAL version 2.7. Munich: Calculix; 2014. Available from: $<\mathrm{http} / /$ web.mit.edu/ calculix_v2.7/CalculiX/ccx_2.7/doc/ccx/index.html $>$.

25. Serway RA, Jewett JA. Physics for Scientists and Engineers. Volume 1. Belmont: Cengage Learning; 2009.

26. Dieter G, Kuhn H, Semiatin S, eds. Handbook of Workability and Process Design. Materials Park: ASM International; 2003. 